\title{
What is the best alternative if the aortic valve cannot be repaired?
}

\author{
Amine Mazine ${ }^{1}$, Ismail El-Hamamsy ${ }^{2}$ \\ ${ }^{1}$ Division of Cardiac Surgery, University of Toronto, Toronto, ON, Canada; ${ }^{2}$ Division of Cardiac Surgery, Montreal Heart Institute and Université \\ de Montréal, Montreal, QC, Canada \\ Correspondence to: Ismail El-Hamamsy, MD, PhD. Division of Cardiac Surgery, Montreal Heart Institute, 5000 Belanger St. East, Montreal QC H1T \\ 1C8, Canada. Email: i.elhamamsy@icm-mhi.org.
}

Submitted Mar 25, 2019. Accepted for publication Apr 05, 2019.

doi: $10.21037 /$ acs.2019.04.03

View this article at: http://dx.doi.org/10.21037/acs.2019.04.03

Aortic valve repair is the preferred treatment for aortic insufficiency. When the valve is not repairable, options for valve substitutes include bioprosthetic valves, mechanical valves, aortic valve homografts and a pulmonary autograft (Ross procedure). The choice of an aortic valve substitute must be made judiciously, as each of these options has benefits and drawbacks that significantly impact long-term prognosis and quality of life. Current guidelines recommend the use of a mechanical valve in patients less than 50 years and a bioprosthetic valve in patients more than 70 years (1). Nonetheless, with the advent of transcatheter aortic valve replacement-and the promise of valve-in-valve therapybioprosthetic valves are increasingly being implanted in young patients (2). Several contemporary studies have shown that both bioprosthetic and mechanical valves are associated with excess mortality when implanted in young and middleaged adults. All the more, this excess mortality is inversely proportional to patient age at the time of surgery (i.e., the youngest patients have the largest excess mortality) $(3,4)$.

The shortcomings associated with the use of mechanical and bioprosthetic valves in younger patients are undoubtedly related to the inability of these inert, acellular prostheses to recapitulate the sophisticated functions of the living aortic valve (5). This issue is compounded in patients who would be considered for aortic valve repair, many of whom are young and otherwise healthy. Given their longer life expectancy, every effort should be made to provide these patients with a living aortic valve substitute, to minimize their cumulative lifetime hazard of valve-related complications. Currently, the Ross procedure is the only available replacement operation that guarantees long-term viability of the aortic valve.

Several studies have shown that in young and middleaged adults, the Ross procedure is associated with better long-term survival and freedom from valve-related complications compared with other forms of aortic valve replacement, when performed in centers of excellence (6-8). Importantly, the Ross procedure is the only operation that can restore normal life expectancy in young and middleaged adults undergoing aortic valve replacement. Indeed, the majority of contemporary cohort studies documenting long-term ( $\geq 15$ years) outcomes of the Ross procedure have reported a survival that is similar to that of the age- and sex-matched general population (7). In contrast, no study on conventional AVR in young and middle-aged adults has demonstrated restored survival compared with the matched general population, including highly selected series (4).

In addition to improved survival, the Ross procedure confers enhanced quality of life compared with prosthetic AVR, an important consideration in young and middleaged patients who are typically more active than their older counterparts. Several studies have reported higher scores on both the physical and psychological health subscales of the short-form health survey (SF-36) in patients who undergo the Ross operation compared with mechanical AVR (7). This enhanced quality of life is due to several factors, including the avoidance of anticoagulation and the superior hemodynamic performance of the pulmonary autograft. Indeed, whereas mechanical and bioprosthetic valves fix the annulus in place — and are hence inherently obstructive-the pulmonary autograft preserves the mobility of all components of the aortic root, resulting in lower mean transaortic gradients and more physiological flow patterns, even with exercise.

Patients who undergo aortic valve repair typically present with predominant severe aortic insufficiency. Previous studies have identified preoperative aortic insufficiency as a predictor of late autograft failure after the Ross procedure, 
particularly when associated with a large aortic annulus ( $\geq 27 \mathrm{~mm}$ ) (9). Nevertheless, it is noteworthy that all large contemporary Ross series have reported low rates of reoperation (ranging between $1 \%$ and $2 \%$ per patient-year), despite the inclusion of a significant proportion of patients with pure aortic insufficiency (ranging from 20\% to $50 \%$ ) (7). Furthermore, a number of technical modifications and adjunct measures have been proposed to mitigate the risk of late failure in these patients. These include the addition of an extra-aortic annuloplasty using a circular Dacron ring or reinforcement of the pulmonary autograft with a prosthetic Dacron graft (7). Using some of these adjunct measures, contemporary series of patients undergoing the Ross procedure for pure aortic insufficiency have demonstrated excellent long-term (up to 20 years) freedom from reoperation and/or recurrent aortic insufficiency, demonstrating that the Ross procedure can be carried out with good durability in these patients using a tailored approach (10). These data, however, underscore the critical role of mentorship in training the younger generation of aortic surgeons and the importance of establishing centers of excellence for aortic root reconstructive surgery.

In summary, valve repair is the preferred treatment for severe aortic insufficiency, because it allows patients to keep their native, living aortic valve. When repair is not feasible, the ideal alternative is to use a replacement option that allows for placement of a living substitute in the aortic position. The Ross procedure is, by definition, the only replacement operation that achieves this goal. Current evidence suggests that in the absence of a contraindication (i.e., familial aortopathy, connective tissue disorder, limited life expectancy $\leq 15$ years) it should be the operation of choice in young and middle-aged adults with a nonrepairable aortic valve. Future iterations of major society guidelines should consider the accumulating evidence favoring the Ross procedure over other forms of aortic valve replacement in non-elderly adults who are not eligible for valve repair, and support a greater role for the pulmonary autograft in the treatment of these patients.

\section{Acknowledgments}

None.

\section{Footnote}

Conflicts of Interest: The authors have no conflicts of interest to declare.

\section{References}

1. Nishimura RA, Otto CM, Bonow RO, et al. 2014 AHA/ ACC guideline for the management of patients with valvular heart disease: a report of the American College of Cardiology/American Heart Association Task Force on Practice Guidelines. J Am Coll Cardiol 2014;63:e57-185.

2. Isaacs AJ, Shuhaiber J, Salemi A, et al. National trends in utilization and in-hospital outcomes of mechanical versus bioprosthetic aortic valve replacements. J Thorac Cardiovasc Surg 2015;149:1262-9.e3.

3. Bourguignon T, Bouquiaux-Stablo AL, Candolfi $\mathrm{P}$, et al. Very long-term outcomes of the Carpentier-Edwards Perimount valve in aortic position. Ann Thorac Surg 2015;99:831-7.

4. Bouhout I, Stevens LM, Mazine A, et al. Long-term outcomes after elective isolated mechanical aortic valve replacement in young adults. J Thorac Cardiovasc Surg 2014;148:1341-6.e1.

5. Chester AH, El-Hamamsy I, Butcher JT, et al. The living aortic valve: From molecules to function. Glob Cardiol Sci Pract 2014;2014:52-77.

6. El-Hamamsy I, Eryigit Z, Stevens LM, et al. Longterm outcomes after autograft versus homograft aortic root replacement in adults with aortic valve disease: a randomised controlled trial. Lancet 2010;376:524-31.

7. Mazine A, El-Hamamsy I, Verma S, et al. Ross Procedure in Adults for Cardiologists and Cardiac Surgeons: JACC State-of-the-Art Review. J Am Coll Cardiol 2018;72:2761-77.

8. Sharabiani MT, Dorobantu DM, Mahani AS, et al. Aortic Valve Replacement and the Ross Operation in Children and Young Adults. J Am Coll Cardiol 2016;67:2858-70.

9. David TE, Woo A, Armstrong S, et al. When is the Ross operation a good option to treat aortic valve disease? J Thorac Cardiovasc Surg 2010;139:68-73; discussion 73-5.

10. Poh CL, Buratto E, Larobina M, et al. The Ross procedure in adults presenting with bicuspid aortic valve and pure aortic regurgitation: $85 \%$ freedom from reoperation at 20 years. Eur J Cardiothorac Surg 2018;54:420-6.

Cite this article as: Mazine A, El-Hamamsy I. What is the best alternative if the aortic valve cannot be repaired? Ann Cardiothorac Surg 2019;8(3):399-400. doi: 10.21037/ acs.2019.04.03 